\title{
Cocaine treatment alters oxytocin receptor binding but not mRNA production in postpartum rat dams ${ }^{\star}$
}

\author{
T.M. Jarrett ${ }^{\star}$, M.S. McMurray, C.H. Walker, and J.M. Johns \\ Department of Psychiatry, The University of North Carolina at Chapel Hill, CB\# 7096, 436 Taylor \\ Hall, Chapel Hill, NC 27599-7096, USA
}

\begin{abstract}
Gestational cocaine treatment in rat dams results in decreased oxytocin (OT) levels, up-regulated oxytocin receptor (OTR) binding density and decreased receptor affinity in the whole amygdala, all concomitant with a significant increase in maternal aggression on postpartum day six. Rat dams with no gestational drug treatment that received an infusion of an OT antagonist directly into the central nucleus of the amygdala (CeA) exhibited similarly high levels of maternal aggression towards intruders. Additionally, studies indicate that decreased OT release from the hypothalamic division of the paraventricular nucleus $(\mathrm{PVN})$ is coincident with heightened maternal aggression in rats. Thus, it appears that cocaine-induced alterations in OT system dynamics (levels, receptors, production, and/or release) may mediate heightened maternal aggression following cocaine treatment, but the exact mechanisms through which cocaine impacts the OT system have not yet been determined. Based on previous studies, we hypothesized that two likely mechanisms of cocaine's action would be, increased OTR binding specifically in the CeA, and decreased OT mRNA production in the PVN. Autoradiography and in situ hybridization assays were performed on targeted nuclei in brain regions of rat dams on postpartum day six, following gestational treatment twice daily with cocaine $(15 \mathrm{mg} / \mathrm{kg})$ or normal saline $(1 \mathrm{ml} / \mathrm{kg})$. We now report cocaineinduced reductions in OTR binding density in the ventromedial hypothalamus (VMH) and bed nucleus of the stria terminalis (BNST), but not the CeA. There was no significant change in OT mRNA production in the $\mathrm{PVN}$ following cocaine treatment.
\end{abstract}

\section{Keywords}

Bed nucleus of the stria terminalis; Central nucleus of the amygdala; Cocaine; Hypothalamic paraventricular nucleus; mRNA; oxytocin; Rats; Receptors; Supraoptic nucleus; Ventral medial hypothalamus

\section{Introduction}

Recently, there has been increased interest in central OT system involvement in maternal aggressive behavior in rats, specifically if, and how OT might be mediating this behavior. Otherwise untreated rats displayed increased levels of maternal aggression towards intruders on postpartum day six following infusion of the OT antagonist, $\mathrm{d}\left(\mathrm{CH}_{2}\right)_{5}$,

[ $\mathrm{Tyr}(\mathrm{Me})^{2}-\mathrm{Thr}^{4}-\mathrm{Tyr}-\mathrm{NH}_{2}^{9}$ ]- vasotocin, directly and specifically, into the CeA (Lubin et al., 2003). Conversely, OT infused directly into the CeA and BNST, decreased maternal

\footnotetext{
This project was supported by NIH grant DA R01-13283A1 awarded to J.M.J.

(C) 2006 Elsevier Ltd. All rights reserved.

*Corresponding author. Tel.: +1 919966 5961; fax: + 1919843 5730. tjarrett@ med.unc.edu (T.M. Jarrett). URL: www.unc.edu/ tjarrett (T.M. Jarrett).
} 
aggression in lactating rats on postpartum days five-seven (Consiglio et al., 2005). Other studies suggest that OT release in the PVN and CeA may play an important role in normal maternal aggression (Bosch et al., 2004, 2005). Additionally, selective inhibition and destruction of oxytocinergic parvocellular neurons in the hypothalamic PVN have been proposed as a possible mechanism for alteration of maternal aggression through reduction of central OT levels (Giovenardi et al., 1998). Thus, there is growing evidence of a role for OT mediation of maternal aggressive behavior, primarily through the CeA.

Although it is adaptive for rat dams to protect their young from intruders, non-protective or overly aggressive behavior is not considered adaptive. Rat dams treated throughout gestation with cocaine exhibited significantly increased aggression towards intruders while exhibiting generally poorer pup directed maternal behavior (Johns et al., 1994). Co-incident with higher levels of maternal aggression on postpartum day six, cocaine treated rat dams had significantly lower OT levels in the whole amygdala (Johns et al., 1998). Furthermore, as characterized by a saturation binding assay, cocaine treatment resulted in an increase in OTR binding and decreased OTR affinity in the amygdala of cocaine treated rat dams on postpartum day six (Johns et al., 2004). Cocaine-induced alterations of one or more aspects of the OT system (binding, levels, release, production) have been proposed as the mechanism through which cocaine increases maternal aggression in rat dams (Johns et al., 1994, 1998). Based on previous evidence, the CeA appears to be the most likely candidate for probable OTR receptor dysregulation previously reported in the whole amygdala of cocaine-treated rat dams.

Since projections from the parvocellular region of the PVN to various brain regions within the central nervous system (CNS) are strongly implicated in maternal behavior and aggression (Bale et al., 2001; Ingram and Moos, 1992; Numan and Corodimas, 1985; Pedersen, 1997), disruption of OT production in the PVN could play an important role in cocaine's effects on other OT system dynamics (levels or release). Production of OT, largely restricted to the PVN and supraoptic nucleus (SON) (Burbach et al., 1992; Numan and Insel, 2003; Van Tol et al., 1988; Zingg and Lefebvre, 1988), has not been previously investigated in a rodent model of gestational cocaine treatment.

The present study tested the specific hypotheses that OTR density would be increased in the $\mathrm{CeA}$ and that OT mRNA production would be decreased in the PVN of rat dams treated with cocaine during gestation compared to saline treated controls on postpartum day six.

\section{Methods}

\subsection{Subjects}

Virgin female Sprague-Dawley rats (200-250 g) were group housed in a temperature and humidity controlled room for a one week habituation period prior to mating. Females were then singly housed with a sexually mature male until conception was noted by the presence of a sperm plug, and if necessary, confirmation was made by vaginal smears. On the day a sperm plug was present, designated as gestation day zero (GD 0), the female was removed from the breeding cage, randomly assigned to a treatment group, and individually housed. Pregnant females were maintained on a reverse $12 \mathrm{~h}$ light-dark cycle (with lights on at 2100 hours for 7 days), then transferred to a room with a regular light cycle (lights on at 0700 hours for the remainder of the experiment), a procedure that generally results in the majority of dams delivering their litters during daylight hours (Mayer and Rosenblatt, 1998). All procedures were conducted under federal and institutional animal care and use committee guidelines for humane treatment of laboratory subjects. 


\subsection{Dam treatment}

Treatment groups included: cocaine and saline dams given subcutaneous (sc) injections of cocaine $(15 \mathrm{mg} / \mathrm{kg}$ cocaine hydrochloride, Sigma-Aldrich Co., MO, dissolved in $0.9 \%$ normal saline in a total volume of $1 \mathrm{ml} / \mathrm{kg}$, with dose calculated as the free base;) or saline $(0.9 \% 1 \mathrm{ml} / \mathrm{kg}$ ) respectively, twice daily on alternating flanks throughout gestation (GD 120 at approximately 0900 and 1600). Cocaine-treated dams had free access to water and food (Purina rat chow) but saline-treated dams were pair-fed to cocaine-treated dams to control for the anorectic effects of cocaine. Pair feeding insured that on any specific gestation day, controls received the same amount of food eaten on average by a cocainetreated dam on that same respective gestation day, as previously described (Johns et al., 1994).

Immediately following parturition, designated as postpartum day one, pups were removed, weighed, counted, and their gender recorded. All dams then received eight surrogate pups born within $8 \mathrm{~h}$ of their delivery to control for potential differences in maternal behavior resulting from differential pup cues due to offspring prenatal drug exposure. Each dam and her foster litter were then returned to the dam's home cage in the colony room and monitored daily until sacrifice on postpartum day six.

\subsection{Brain collection and slice preparation}

On postpartum day six cocaine and saline treated subjects were decapitated, their whole brains extracted, immediately flash frozen on dry ice for $5 \mathrm{~min}$, and finally stored at $-80{ }^{\circ} \mathrm{C}$ until they were sectioned. Twenty micrometer coronal sections were serially collected from the CeA and PVN with a cryostat (Leica CM 3050, Germany) for the autoradiography and in situ hybridization assays, using a stereotaxic rat brain atlas as a reference (Paxinos and Watson, 1997).

Regions of interest included, the entire PVN, encompassing the magnocellular and parvocellular regions with the $\mathrm{SON}$ as a control region; the CeA including lateral and medial portions with the entire VMH and BNST regions analyzed as associated regions to control for binding specificity. Slices were thaw mounted onto Superfrost Plus Slides (Fisher Scientific International Inc., $\mathrm{NH}$ ) and returned to storage at $-80{ }^{\circ} \mathrm{C}$ until time of assay.

\subsection{Receptor autoradiography}

OT autoradiography was performed on sections from 9 of 14 and 7 of 12 randomly selected cocaine and saline treated dams respectively, using ${ }^{125} \mathrm{I}$-OTA, $\left[\mathrm{d}\left(\mathrm{CH}_{2}\right)_{5}, \mathrm{O}-\mathrm{Me}-\mathrm{Tyr}^{2}, \mathrm{Thr}^{4}\right.$, $\mathrm{Tyr}^{9}, \mathrm{Orn}^{8}$ ]-vasotocin (New England Nuclear, MA) as described previously (Francis et al., 2002). Briefly, sections were allowed to thaw at room temperature, immersed in a fixative of $0.1 \%$ paraformaldehyde in phosphate-buffered saline $(1 \mathrm{~g} / \mathrm{L}$ paraformaldehyde, 2 pellet/L $\mathrm{NaOH} \mathrm{pH}$ to 7.4) at room temperature for $2 \mathrm{~min}$, and then rinsed twice for $10 \mathrm{~min}$ in Tris Buffer (50 mM, pH with $\mathrm{HCl}$ to 7.4). Tracer binding employed $30 \mathrm{ml}$ of a solution of ${ }^{125} \mathrm{I}$ OTA, $\left[\mathrm{d}\left(\mathrm{CH}_{2}\right)_{5}, \mathrm{O}-\mathrm{Me}_{\mathrm{Tyr}}{ }^{2}, \mathrm{Thr}^{4}, \mathrm{Tyr}^{9}, \mathrm{Orn}^{8}\right]$-vasotocin in buffer $(50 \mathrm{mM}$ Tris, $10 \mathrm{mM}$ $\mathrm{MgCl}, 0.1 \% \mathrm{BSA}, 0.05 \%$ bacitracin, $\mathrm{pH} 7.4$ ) at a concentration of $50 \mathrm{pM}$. Non-specific binding was determined by incubation of adjacent sections with the radioactive ligand described above and $50 \mu \mathrm{M}$ of an unlabeled specific OT ligand, $\mathrm{Thr}^{4}, \mathrm{Gly}^{7}$ oxytocin (Bachem, CA). Buffer was applied to the sections in vertical slide holders at room temperature for $60 \mathrm{~min}$. Following tracer binding, the slides were washed three times (5 min) with Tris/ $\mathrm{MgCl}$ buffer (50 $\mathrm{mM}$ Tris, $10 \mathrm{mM} \mathrm{MgCl}$, $\mathrm{pH}$ with $\mathrm{HCl}$ to 7.4 ) at room temperature. Slides were then washed for $30 \mathrm{~min}$ in a circulating Tris/ $\mathrm{MgCl}$ buffer, followed by a $2 \mathrm{~s}$ wash in distilled water before they were rapidly dried with gently forced cool air. The slide sections along with a series of ${ }^{125}$ I-microscale standards (Amersham, UK) were 
exposed on Kodak BioMax MR film (Kodak, NY) for 3 days and developed with GBX developer and fixer (Kodak, NY) to obtain images for quantification.

\subsection{In situ hybridization}

OT in situ hybridization was performed on 8 of 14 and 7 of 12 randomly selected cocaine and saline-treated dams respectively using a single, 41 base, ${ }^{35} \mathrm{~S}$-oligionucleotide probe (GGG CTC AGC GCT CGG AGA AGG CAG ACT CAG GGT CGC AGG CG) complementary to nucleotides 906-946 of the rat OT mRNA (GenBank Accession Number K01701).

Sections were processed for OT in situ hybridization as described previously (Wang et al., 2000), with slight modifications for this study. Briefly, sections were fixed in $4 \%$ paraformaldehyde and rinsed in phosphate-buffered saline. Then they were rinsed in $1.5 \%$ triethanolamine and treated with $0.25 \%$ acetic anhydride, defatted in chloroform and dehydrated in a series of graded concentrations of ethanol. Each slide was incubated at 37 ${ }^{\circ} \mathrm{C}$ overnight with $200 \mu \mathrm{l}$ of hybridization solution (50\% formamide, $1 \times$ Denhardt's solution, $10 \%$ dextran sulfate, $0.3 \mathrm{M} \mathrm{NaCl}, 0.8 \times$ Tris/EDTA, $8 \mathrm{mM}$ dithiothreitol and $1 \mathrm{mg} / \mathrm{ml}$ tRNA) containing about $1 \times 10^{6} \mathrm{cpm}$ of oxytocin oligonucleotide probe which was labeled with ${ }^{35} \mathrm{~S}$ dATP (Perkin-Elmer, MA) using Tdt and purified with a QiaQuick nucleotide removal kit (Qiagen, CA). After the incubation, the slides were washed in saline-sodium citrate buffer, dehydrated with ethanol/ammonium acetate, and dried. Slides were placed on Biomax MR Film (Kodak, NY) for $60 \mathrm{~min}$ and developed. Specificity controls included treating sections with a sense probe for the OT peptide during probe development, which did not produce any labeling.

\subsection{Photomicrograph production and image analysis}

Digital images of autoradiograms were obtained using a ScanMaker 9800 XL Flatbed Scanner with Transparent Media Adapter (Microtex Inc. CA) connected to a Macintosh ${ }^{\circledR}$ computer. Images were imported into Silverfast MicroIT8 (LaserSoft Inc., Germany), and no cropping or adjustments for brightness and contrast were made to clarify the scientific point of interest.

Autoradiographic binding was quantified from the digitized autoradiograms using the NIH image program (http://rsb.info.nih.gov/nih-image) for the Macintosh ${ }^{\circledR}$. For OTR, optical densities were converted to disintegrations per minute per milligram (DPM/mg) tissue equivalents, using the ${ }^{125}$ I autoradiograph standards developed with the slide images. All sections were coded to obscure the identity of the tissue and each region of interest in OTR binding was measured bilaterally from 10 sections per area, per animal.

For OT in situ hybridization, optical densities were not converted to any standardized unit of radioactive decay as appropriate standards are not currently available on the market. Comparisons between groups were based on tissue optical density measurements, minus background levels of adjacent blank film.

\subsection{Statistical analysis}

Gestational data, including group mean comparisons of gestation length, dam weight gain, number of pups, pup gender, litter weight, and culled foster litter weight gain (postpartum days one through six) were analyzed using a one-way analysis of variance (ANOVA).

Brain sections from cocaine and saline treated animals were compared to standard sections. Reported numbers are presented as DPM/mg for receptor binding densities and optical density (OD) for OT mRNA production. Data presented in tables and figures include the 
mean \pm SEM per group. Specific binding was calculated by subtracting non-specific binding from total binding for each area. Binding and OD data were analyzed with a one-way ANOVA for independent measures, followed by Tukey highest significant difference (HSD) posthoc analyses $(p \leq 0.05)$ when appropriate.

\section{Results}

\subsection{Gestational data}

As shown in Table 1, cocaine treated dams gained significantly less weight over gestation than did saline control dams $[F(1,24)=4.31 ; p \leq 0.05)]$. There were no group differences on the measures of gestation length for dams or any of the litter related measures.

\subsection{OT receptor autoradiography}

Table 2 illustrates the binding values from targeted regions of interest, with significant group differences highlighted in bold print and denoted with an asterisk. The results, shown in Fig. 1, include graphical representation of regions, along with representative autoradiographs. Cocaine treatment resulted in significantly lower OTR binding density in the $\mathrm{VMH}[F(1,13)=5.76 ; p \leq 0.05)]$ and BNST $[F(1,14)=4.41 ; p \leq 0.05)]$ compared to saline treatment, with no significant group differences apparent in CeA OT binding.

\subsection{In situ hybridization}

OT mRNA production was, as expected, highly restricted to the hypothalamic PVN and SON. As illustrated in the graphs and representative autoradiographs in Fig. 2 and shown numerically in Table 3 , there were no significant differences between cocaine and saline treated dams in OT mRNA production, in either region.

\section{Discussion}

Although our original hypotheses were not supported, we do report a significantly lower density of OTR binding in the VMH and BNST of cocaine-treated dams compared to salinetreated controls. These findings, along with the OT and OTR alterations previously reported in the whole amygdala, hippocampus, medial preoptic area and ventral tegmental area (Huber et al., 2005; Johns et al., 1998, 2004), indicate most importantly, a pervasive dysregulation of the OT system in cocaine treated lactating rat dams. Also of significance, the findings indicate cocaine related OTR alterations in nuclei associated with maternal behavior/aggression that have not been previously reported, which may prove to have behavioral significance perhaps acting as part of a general inhibitory circuit along with other previously indicated regions of interest. The present report, along with the recent findings from Consiglio et al. (2005), indicates a possible role for OT regulation in the BNST as at least a partial mediator of maternal aggression in lactating rats. The BNST, which interconnects the VMH and amygdala (Palkovits and Zaborsky, 2005), is considered to be morphologically and functionally associated with the CeA (Alheid and Heimer, 1988; Canteras et al., 1995; Cushing and Kramer, 2005; Sun et al., 1991; Veinante and FreundMercier, 1998). Previously, this structure has been most often associated with maternal behavior (Insel, 1992; Kendrick et al., 1992; Numan and Numan, 1996). If as reported, higher OT levels in the BNST result in decreased aggression (Consiglio et al., 2005), a cocaine induced decrease in OTR with subsequently reduced binding, could possibly have the inverse effect on maternal aggressive behavior. Further studies will be needed to clarify the role of OT and OTR in the BNST both in the mediation of normal maternal aggressive behavior, and more specifically in cocaine induced hyper-aggression. 
The VMH is also rich in OTR binding, particularly in the more ventral portions of the nucleus (Freund-Mercier et al., 1988; Tribollet et al., 1988; van Leeuwen et al., 1985). Interestingly, several studies report VMH projections to the CeA (Kruk et al., 1983, 1984a,b; Lammers et al., 1988; Roeling et al., 1994) and although the VMH is more typically associated with sexual (Pfaff and Schwartz-Giblin, 1988) and feeding behavior (Oomura, 1988), several studies using lesion (Grossman, 1972) and brain stimulation (Kruk et al., 1984b; Mos et al., 1987) paradigms have linked this structure to non-maternal aggression. Other studies using central GABA antagonists (Hansen and Ferreira, 1986), as well as knife cut, electrocoagulative, and ibotenic lesions of the VMH (Hansen, 1989), link this region more specifically to maternal aggression. Though we did not find a significant change in OTR binding in the CeA of cocaine treated animals as predicted, this could possibly be a reflection of methodological differences between this and our previous study (Johns et al., 2004), but future studies will elucidate the discrepancy in findings. Additional studies will be needed to examine behavioral correlations as the present findings did not include behavioral data and just as with the BNST, the role of the VMH in maternal aggressive behavior remains to be characterized. It may be that OTR changes in these two regions may have little to do with measureable behavior, considering that OTR are regulated in the CNS by glucocorticoids (Liberzon et al., 1994; Liberzon and Young, 1997), and stress related activation of the HPA axis following cocaine withdrawal could alter OTR expression unrelated to behavioral involvement. The present findings indicate the importance of conducting further studies of these two regions.

Prior to this study, cocaine's influence on OT mRNA production had not been reported for dams treated with cocaine during gestation. Decreases in OT production in the parvocellular region of the PVN were hypothesized based on previous studies (Johns et al., 1998) and the possible relevance of OT projections from the parvocellular region of the PVN to limbic structures (Newman, 1999; Sawchenko and Swanson, 1983). We were unable to distinguish differences between the parvocellular and magnocellular regions of the PVN though all measurements were consistent for both treatment groups. There was only a slight, nonsignificant increase in mRNA in the SON and PVN, leading us to believe that OT mRNA production is probably not a factor in cocaine-induced OT dysregulation on postpartum day six, although earlier changes cannot be ruled out. Based on these findings, further studies will examine cocaine's effects on OT release, stress related changes as relates to peripheral OT changes, and a determination of whether OT changes in the VMH and BNST have relevance for behavior following cocaine treatment.

\section{Acknowledgments}

This work was supported by an NIH grant RO1-DA13283 awarded to J. Johns. We would like to acknowledge the assistance of Dr. Larry Young, our consultant for this project and Dr. Gary Duncan and his lab members who assisted us with the assays.

\section{References}

Alheid GF, Heimer L. New perspectives in basal forebrain organization of special relevance for neuropsychiatric disorders: the striatopallidal, amygdaloid, and corticopetal components of substantia innominata. Neuroscience. 1988; 27:1-39. [PubMed: 3059226]

Bale TL, Davis AM, Auger AP, Dorsa DM, McCarthy MM. CNS region-specific oxytocin receptor expression: importance in regulation of anxiety and sex behavior. J Neurosci. 2001; 21:2546-2552. [PubMed: 11264328]

Bosch OJ, Kromer SA, Brunton PJ, Neumann ID. Release of oxytocin in the hypothalamic paraventricular nucleus, but not central amygdala or lateral septum in lactating residents and virgin intruders during maternal defence. Neuroscience. 2004; 124:439-448. [PubMed: 14980393] 
Bosch OJ, Meddle SL, Beiderbeck DI, Douglas AJ, Neumann ID. Brain oxytocin correlates with maternal aggression: link to anxiety. J Neurosci. 2005; 25:6807-6815. [PubMed: 16033890]

Burbach JP, Adan RA, de Bree FM. Regulation of oxytocin gene expression and forms of oxytocin in the brain. Ann NY Acad Sci. 1992; 652:1-13. [PubMed: 1626823]

Canteras NS, Simerly RB, Swanson LW. Organization of projections from the medial nucleus of the amygdala: a PHAL study in the rat. J Comp Neurol. 1995; 360:213-245. [PubMed: 8522644]

Consiglio AR, Borsoi A, Pereira GA, Lucion AB. Effects of oxytocin microinjected into the central amygdaloid nucleus and bed nucleus of stria terminalis on maternal aggressive behavior in rats. Physiol Behav. 2005; 85:354-362. [PubMed: 15935410]

Cushing BS, Kramer KM. Mechanisms underlying epigenetic effects of early social experience: the role of neuropeptides and steroids. Neurosci Biobehav Rev. 2005; 29:1089-1105. [PubMed: 16099507]

Francis DD, Young LJ, Meaney MJ, Insel TR. Naturally occurring differences in maternal care are associated with the expression of oxytocin and vasopressin (V1a) receptors: gender differences. $J$ Neuroendocrinol. 2002; 14:349-353. [PubMed: 12000539]

Freund-Mercier MJ, Stoeckel ME, Dietl MM, Palacios JM, Richard P. Quantitative autoradiographic mapping of neurohypophysial hormone binding sites in the rat forebrain and pituitary gland $-\mathrm{I}$. Characterization of different types of binding sites and their distribution in the Long-Evans strain. Neuroscience. 1988; 26:261-272. [PubMed: 2843790]

Giovenardi M, Padoin MJ, Cadore LP, Lucion AB. Hypothalamic paraventricular nucleus modulates maternal aggression in rats: effects of ibotenic acid lesion and oxytocin antisense. Physiol Behav. 1998; 63:351-359. [PubMed: 9469726]

Grossman SP. Aggression, avoidance, and reaction to novel environments in female rats with ventromedial hypothalamic lesions. J Comp Physiol Psychol. 1972; 78:274-283. [PubMed: 5062000]

Hansen S. Medial hypothalamic involvement in maternal aggression of rats. Behav Neurosci. 1989; 103:1035-1046. [PubMed: 2803551]

Hansen S, Ferreira A. Effects of bicuculline infusions in the ventromedial hypothalamus and amygdaloid complex on food intake and affective behavior in mother rats. Behav Neurosci. 1986; 100:410-415. [PubMed: 3730149]

Huber D, Veinante P, Stoop R. Vasopressin and oxytocin excite distinct neuronal populations in the central amygdala. Science. 2005; 308:245-248. [PubMed: 15821089]

Ingram CD, Moos F. Oxytocin-containing pathway to the bed nuclei of the stria terminalis of the lactating rat brain: immunocytochemical and in vitro electrophysiological evidence. Neuroscience. 1992; 47:439-452. [PubMed: 1641132]

Insel TR. Oxytocin - A neuropeptide for affiliation: evidence from behavioral, receptor autoradiographic, and comparative studies. Psychoneuroendocrinology. 1992; 17:3-35. [PubMed: 1319071]

Johns JM, Noonan LR, Zimmerman LI, Li L, Pedersen CA. Effects of chronic and acute cocaine on the onset of maternal behavior and aggression in Sprague-Dawley rats. Behav Neurosci. 1994; 108:107-112. [PubMed: 8192835]

Johns, JM.; Noonan, LR.; Zimmerman, LI.; McMillen, BA.; Means, LW.; Walker, CH.; Lubin, DA.; Meter, KE.; Nelson, CJ.; Pedersen, CA.; Mason, GA.; Lauder, J. Chronic cocaine treatment alters social/aggressive behavior in Sprague- Dawley rat dams and in their prenatally exposed offspring. In: Harvey, JA.; Kosofsky, BE., editors. Cocaine: Effects on the Developing Brain. Vol. 846. 1998. Annals of the New York Academy of Sciences. :399-404.

Johns JM, Lubin DA, Walker CH, Joyner P, Middleton C, Hofler V, McMurray M. Gestational treatment with cocaine and fluoxetine alters oxytocin receptor number and binding affinity in lactating rat dams. Int J Dev Neurosci. 2004; 22:321-328. [PubMed: 15380831]

Kendrick KM, Keverne EB, Hinton MR, Goode JA. Oxytocin, amino acid and monoamine release in the region of the medial preoptic area and bed nucleus of the stria terminalis of the sheep during parturition and suckling. Brain Res. 1992; 569:199-209. [PubMed: 1540826] 
Kruk MR, van der Poel AM, Meelis W, Hermans J, Mostert PG, Mos J, Lohman AH. Discriminant analysis of the localization of aggression-inducing electrode placements in the hypothalamus of male rats. Brain Res. 1983; 260:61-79. [PubMed: 6681724]

Kruk MR, Van der Laan CE, Meelis W, Phillips RE, Mos J, van der Poel AM. Brain-stimulation induced agonistic behaviour: a novel paradigm in ethopharmacological aggression research. Prog Clin Biol Res. 1984a; 167:157-177. [PubMed: 6542220]

Kruk MR, Van der Laan CE, Mos J, van der Poel AM, Meelis W, Olivier B. Comparison of aggressive behaviour induced by electrical stimulation in the hypothalamus of male and female rats. Prog Brain Res. 1984b; 61:303-314. [PubMed: 6543251]

Lammers JH, Kruk MR, Meelis W, van der Poel AM. Hypothalamic substrates for brain stimulationinduced attack, teeth-chattering and social grooming in the rat. Brain Res. 1988; 449:311-327. [PubMed: 3395851]

Liberzon I, Young EA. Effects of stress and glucocorticoids on CNS oxytocin receptor binding. Psychoneuroendocrinology. 1997; 22:411-422. [PubMed: 9364620]

Liberzon I, Chalmers DT, Mansour A, Lopez JF, Watson SJ, Young EA. Glucocorticoid regulation of hippocampal oxytocin receptor binding. Brain Res. 1994; 650:317-322. [PubMed: 7953698]

Lubin DA, Elliott JC, Black MC, Johns JM. An oxytocin antagonist infused into the central nucleus of the amygdala increases maternal aggressive behavior. Behav Neurosci. 2003; 117:195-201. [PubMed: 12708515]

Mayer AD, Rosenblatt JS. A method for regulating the duration of pregnancy and the time of parturition in Sprague- Dawley rats (Charles River CD strain). Dev Psychobiol. 1998; 32:131136. [PubMed: 9526688]

Mos J, Olivier B, Lammers JH, van der Poel AM, Kruk MR, Zethof T. Postpartum aggression in rats does not influence threshold currents for EBS-induced aggression. Brain Res. 1987; 404:263-266. [PubMed: 3567571]

Newman SW. The medial extended amygdala in male reproductive behavior. A node in the mammalian social behavior network. Ann NY Acad Sci. 1999; 877:242-257. [PubMed: 10415653]

Numan M, Corodimas KP. The effects of paraventricular hypothalamic lesions on maternal behavior in rats. Physiol Behav. 1985; 35:417-425. [PubMed: 2999841]

Numan, M.; Insel, TR. The Neurobiology of Parental Behavior. Springer Verlag; New York: 2003.

Numan M, Numan MA. A lesion and neuroanatomical tract-tracing analysis of the role of the bed nucleus of the stria terminalis in retrieval behavior and other aspects of maternal responsiveness in rats. Dev Psychobiol. 1996; 29:23-51. [PubMed: 8719181]

Oomura Y. Chemical and neuronal control of feeding motivation. Physiol Behav. 1988; 44:555-560. [PubMed: 2853385]

Palkovits, M.; Zaborsky, L. Neural connections of the hypothalamus. In: Morgane, PJ.; Panksepp, J., editors. Handbook of the Hypothalamus. Dekker; New York, NY: 2005. p. 379-509.

Paxinos, G.; Watson, C. The Rat Brain in Stereotaxic Coordinates. Academic Press; San Diego: 1997.

Pedersen, CA. Oxytocin control of maternal behavior: regulation by sex steroids and offspring stimuli. In: Carter, CS.; Lederhendler, II.; Kirkpatrick, B., editors. The Integrative Neurobiology of Affiliation. Vol. 807. 1997. Annals of the New York Academy of Sciences. :126-145.

Pfaff, DW.; Schwartz-Giblin, S. Cellular mechanisms of female reproductive behaviors. In: Knobil, E.; Neill, JD., editors. The Physiology of Reproduction. Raven Press; New York, NY: 1988. p. 1487-1568.

Roeling TA, Veening JG, Kruk MR, Peters JP, Vermelis ME, Nieuwenhuys R. Efferent connections of the hypothalamic "aggression area" in the rat. Neuroscience. 1994; 59:1001-1024. [PubMed: 8058117]

Sawchenko PE, Swanson LW. The organization and biochemical specificity of afferent projections to the paraventricular and supraoptic nuclei. Prog Brain Res. 1983; 60:19-29. [PubMed: 6198687]

Sun N, Roberts L, Cassell MD. Rat central amygdaloid nucleus projections to the bed nucleus of the stria terminalis. Brain Res Bull. 1991; 27:651-662. [PubMed: 1721859] 
Tribollet E, Barberis C, Jard S, Dubois-Dauphin M, Dreifuss JJ. Localization and pharmacological characterization of high affinity binding sites for vasopressin and oxytocin in the rat brain by light microscopic autoradiography. Brain Res. 1988; 442:105-118. [PubMed: 2834008]

van Leeuwen FW, van Heerikhuize J, van der MG, Wolters P. Light microscopic autoradiographic localization of $[3 \mathrm{H}]$ oxytocin binding sites in the rat brain, pituitary and mammary gland. Brain Res. 1985; 359:320-325. [PubMed: 4075153]

Van Tol HH, Bolwerk EL, Liu B, Burbach JP. Oxytocin and vasopressin gene expression in the hypothalamo-neurohypophyseal system of the rat during the estrous cycle, pregnancy, and lactation. Endocrinology. 1988; 122:945-951. [PubMed: 3342761]

Veinante P, Freund-Mercier MJ. Intrinsic and extrinsic connections of the rat central extended amygdala: an in vivo electrophysiological study of the central amygdaloid nucleus. Brain Res. 1998; 794:188-198. [PubMed: 9622626]

Wang ZX, Liu Y, Young LJ, Insel TR. Hypothalamic vasopressin gene expression increases in both males and females postpartum in a biparental rodent. J Neuroendocrinol. 2000; 12:111-120. [PubMed: 10718906]

Zingg HH, Lefebvre DL. Oxytocin and vasopressin gene expression during gestation and lactation. Brain Res. 1988; 464:1-6. [PubMed: 3179741] 


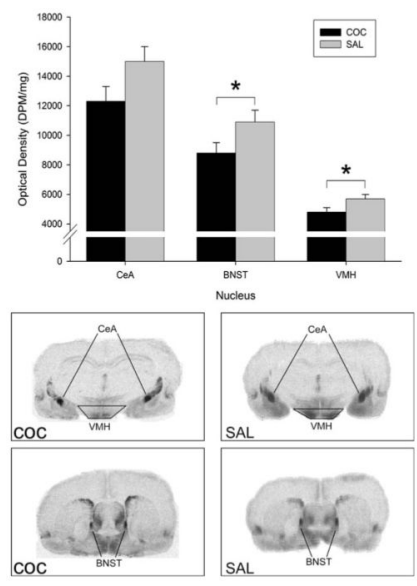

Fig. 1.

Least squares means $( \pm$ SEM) oxytocin receptor (OTR) binding density (DPM/mg) in the central medial and central lateral nucleus of the amygdala $(\mathrm{CeA})$, bed nucleus of the stria terminalis (BNST), and the ventral medial hypothalamus (VMH) in dams on postpartum day six. Nucleus is indicated on the $x$ axis and cocaine (COC) or saline (SAL) treatment is denoted by black or grey bars, respectively. The asterisk indicates that COC treated dams had lower OTR binding levels in the BNST and VMH than SAL treated dams $\left({ }^{*} p \leq 0.05\right)$. Below the graph are representative radiographs of COC and SAL treated dams corroborating lower OTR binding in the BNST and VMH of COC treated dams. 


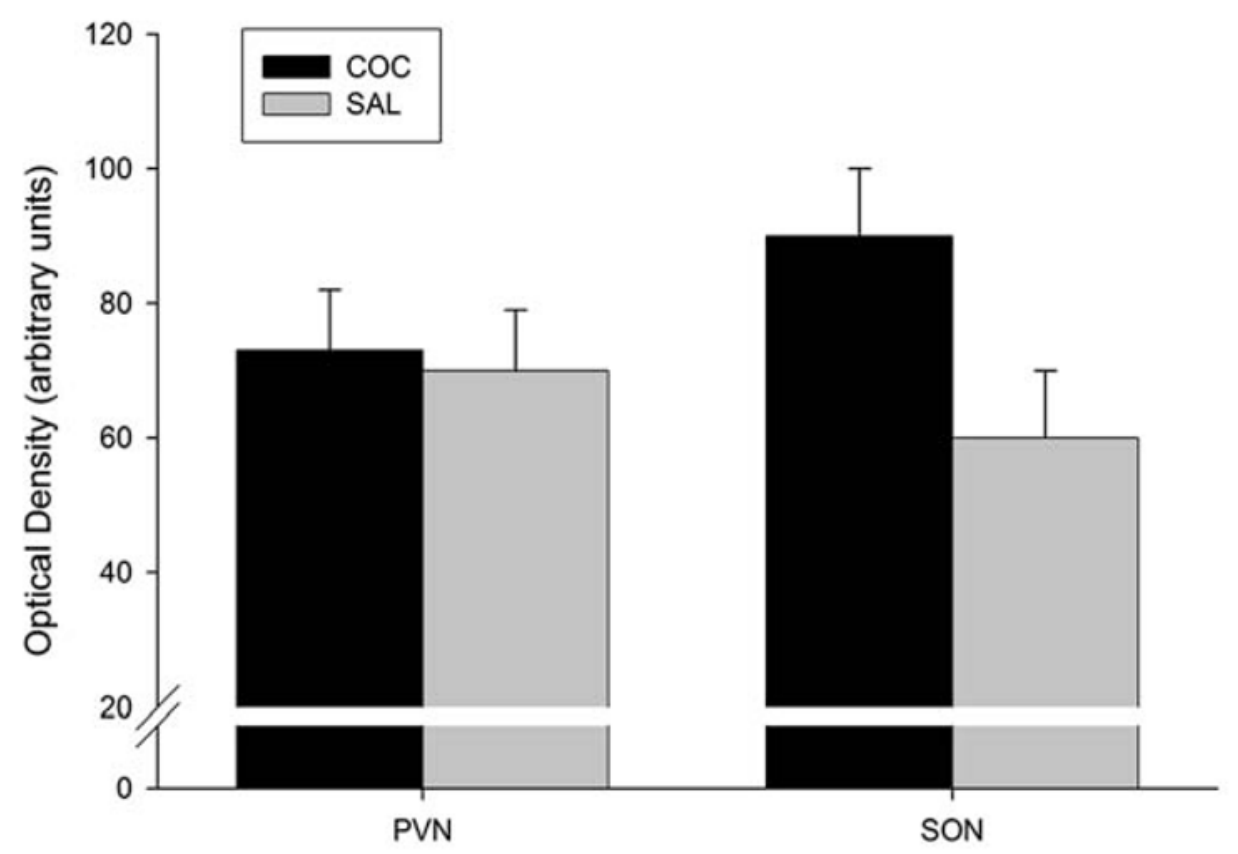

Nucleus

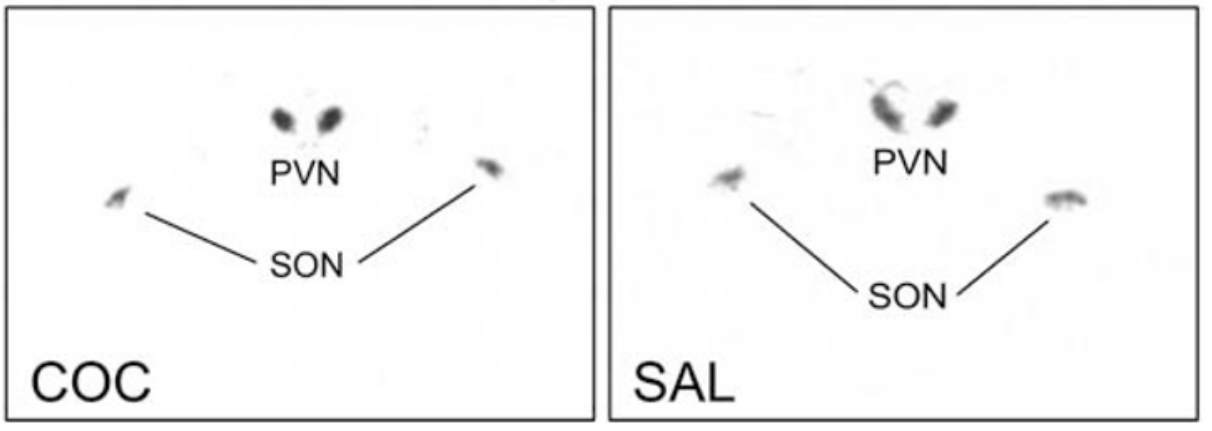

Fig. 2.

Least squares means $( \pm$ SEM) oxytocin (OT) mRNA optical density (OD) in the paraventricular hypothalamic nucleus $(\mathrm{PVN})$ and the supraoptic nucleus (SON) in dams on postpartum day six. Nucleus is indicated on the $x$ axis and cocaine (COC) or saline (SAL) treatment is denoted by black or grey bars, respectively. Below the graph are representative radiographs of COC and SAL treated dams indicating no differences in OT mRNA OD in the SON or PVN of COC treated dams. 


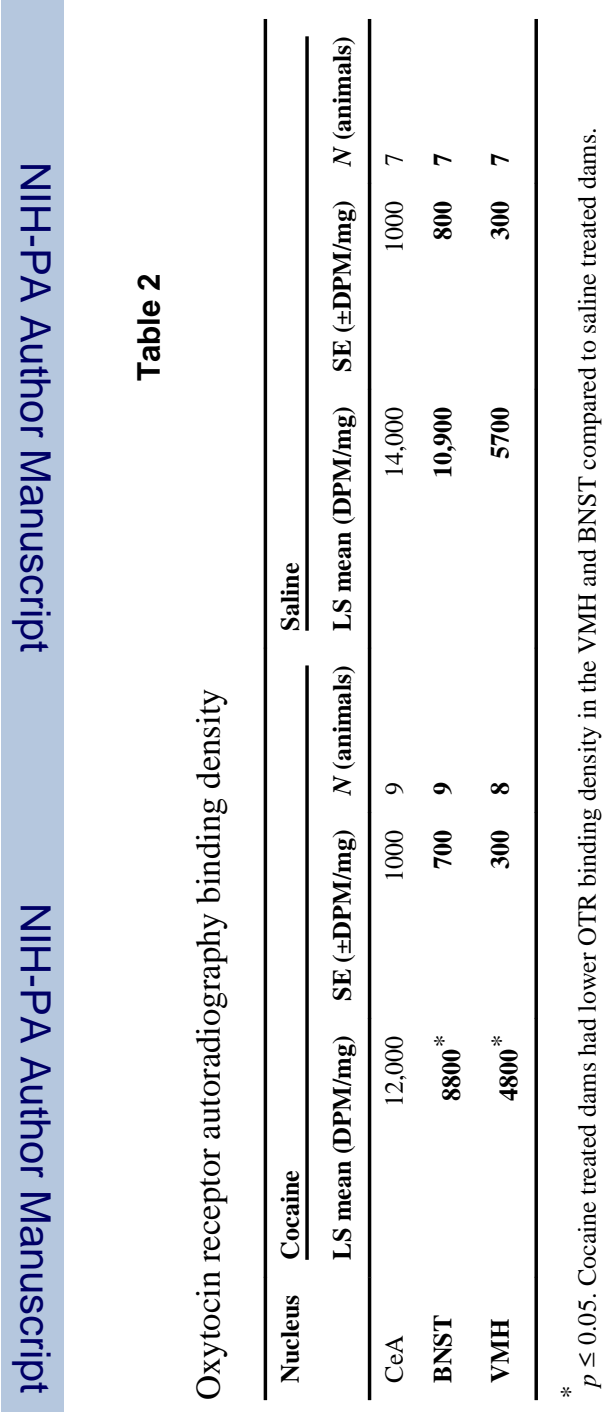




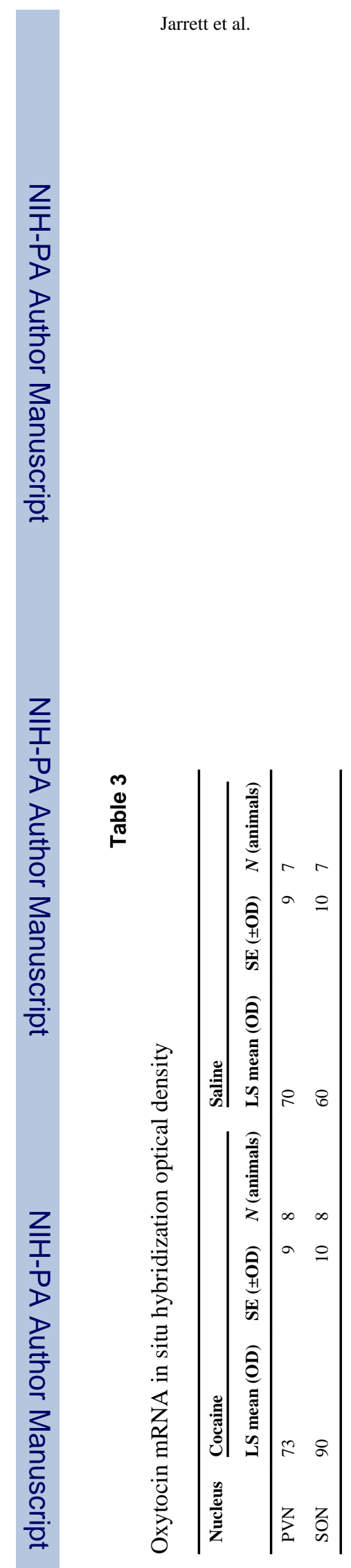

Neuropeptides. Author manuscript; available in PMC 2011 June 7. 